\title{
Effects of curcumin on testis microvascular complication in streptozotocin-induced diabetes rats
}

\section{Wipapan Khimmaktong ${ }^{1}$, Manaras Komolkriengkrai ${ }^{1}$, Piyakorn Boonyoung ${ }^{1}$ and Vipavee Anupunpisit ${ }^{2}$}

${ }^{1}$ Department of Anatomy, Faculty of Science, Prince of Songkla University, Songkhla, 90110, Thailand; ${ }^{2}$ Department of Anatomy, Faculty of Medicine, Srinakharinwirot University, Bangkok, 10110, Thailand

Corresponding author: Wipapan Khimmaktong $\mathrm{PhD}$, Department of Anatomy, Faculty of Science, Prince of Songkla University, Hatyai, Songkhla 90110, Thailand

Submission Date: August $19^{\text {th }}, 2018$, Acceptance Date: January $28^{\text {th }}$, 2018, Publication Date: January $31^{\text {st }}, 2018$

Citation: Khimmaktong W., Komolkriengkrai M., Boonyoung P., Anupunpisit V. Effects of curcumin on testis microvascular complication in streptozotocin-induced diabetes rats. Functional Foods in Health and Disease 2019; 9(1): 34-51. DOI: https://doi.org/10.31989/ffhd.v9i1.542

\section{ABSTRACT}

Background: Diabetes has a significant impact on the impaired function of the reproductive system in the testis.

Objective: The aim of this study was to investigate the effects of curcumin from turmeric on structural changes of testicular tissues and microvasculature in STZ-induced diabetic rats.

Methods: Rats were injected with a single dose of streptozotocin $(60 \mathrm{mg} / \mathrm{kg} \mathrm{BW})$ to induce a diabetic condition. Three days after the injection, rats with a blood sugar level $>250 \mathrm{mg} / \mathrm{dl}$ were considered diabetic. Rats were allocated to one of three groups, diabetic (DM), diabetic rats receiving curcumin (DMC) $(200 \mathrm{mg} / \mathrm{kg} \mathrm{BW})$, and control (C). Testicular tissues were studied eight weeks after the treatment using the histological technique. Testicular microvasculature was examined using the vascular corrosion cast technique under a scanning electron microscope (SEM).

Results: The testicular tissue of DM group showed damaged seminiferous tubules, spermatocytes, and spermatids with necrosis and germ cells degeneration. Destruction of testicular arteries and veins in pampiniform plexus were demonstrated. The destroyed capillaries, arterioles, and venules demonstrated stenosis and shrinkage. The vessel diameter in all DM groups decreased. In the DMC group which received curcumin, the appearance of all seminiferous tubules, spermatogenic, and sertoli cell was normal. The reconstruction and restoration of testicular artery, pampiniform plexus, capillary network, arterioles, and venules 
were clear. As a result of curcumin supplementation, the standard and healthy testis microvasculature was restored. The DMC vessels diameter increased back to a quasi normal condition, particularly at the artery, arteriole, and capillary levels.

Conclusions: The results provided evident for effects of curcumin could be associated with recovering and improvement of the testicular tissues and microvasculatures in diabetic condition.

Keywords: Diabetes mellitus, Streptozotocin, Curcumin, Testis, Microvasculature, Vascular corrosion cast, Scanning electron microscope

\section{BACKGROUND}

Diabetes mellitus is a prolonged disease that incorporates the damaging impact of hyperglycemia characterized by high blood glucose which results from abnormal production and secretion of insulin. A diabetic patient is unable to metabolize carbohydrates, proteins, or fats due to insufficient insulin production or inability of the receptors to respond to insulin. Insulin enables cells to internalize glucose, which is used as an energy source. However, the cells of a diabetic patient are unable to use glucose from the blood stream, resulting in hyperglycaemia, a condition characterized by abnormally high levels of blood glucose. When these high glucose levels are maintained a long time in the bloodstream, severe damage of the retina and kidney microvasculature occurs, even nerve damage [1,2]. Epidemiological studies have demonstrated a high incidence of erectile disfunction (ED) in patients with diabetes mellitus (DM) and a correlation between DM and ED [3]. ED was previously thought to occurr concomitantly with a hormonal imbalance, with low testosterone levels and high gonadotropin and oestradiol. However, subsequent studies failed to verify this association. As the testes produce sperm cells and the hormone testosterone, a defective spermatogenesis may be the result of defective testicular from the diabetes $[4,5]$. Short-term hyperglycemia impairs the fertilizing ability of sperms taken from rat epididymis [6]. Diabetes is known to reduce rat body weight, decrease reproductive organs, and diminish the count of sperms taken from the testis and epididymis, which is associated with a decrease in plasma testosterone levels. The causes of this plasma testosterone decrease in the diabetic syndrome are unknown. Testicular atrophy and hypogonadism occurs in diabetic men [7,8]. Discrete ultrastructural lesions of apical Sertoli cell cytoplasm, spermatogenic disruption, and morphological interstitial testicular tissue abnormalities suggest alterations in the microvasculature [9].

Blood vessels comprise of three tunicae or layers, tunica intima, tunica media, and tunica adventitia. The inner most layer is the tunica intima, which covers the vessel luminal side with a single layer of endothelial cells. This layer is surrounded by a matrix of extracellular connective tissue made of proteoglycans and collagen, and then by a layer of elastic cells. Depending on the vessel size, this elastic layer can have various thickness. The next layer, the tunica media, consists of smooth muscle cells surrounded by a thin elastic lamina. The tunica media is the thickest layer of a vessel. The outer most layer, the tunica adventitia, consists of a collagen matrix with intercalated fibroblasts and vascular smooth muscle cells.

The atherosclerosis develops with similar histological changes in diabetic and non-diabetic patients. After an endothelial injury, smooth muscle cell proliferate, foam cells develop and infiltrate the area. Then, platelets are activated, accelerating inflammation. Changes in blood 
flow results in altered haemodynamic forces and injury to the endothelial cells from external sources, which determine where in the vessel the lesion will occur [10].

The cytotoxic action of streptozotocin (STZ) involve DNA bases alkylation occurring at specific sites and damage by free-radicals produced during STZ metabolism. DNA damage caused by STZ can be severe, resulting in cell death by apoptosis or necrosis. Diabetic individuals and experimental animals develops high oxidative stress [11]. Turmeric is traditionally considered an anti-inflammatory remedy. Recent studies have shown that curcumin, the active compound of turmeric possesses potent antioxidant and anti-inflammatory activities, have been investigated in several systems [12-15]. Curcumin can modulate several transcriptional factors [16-22], cytokines [23-27], growth factors (28-30), kinases (31-33), and other enzymes [34-36].

As several diseases result from dysregulated inflammation, it is important to find antiinflammatory agents that are safe and effective. Morphological changes in testis of diabetic rats are known (37). However, it is unknown which morphological changes in the testicular blood vessels may result from the treatment and supplementation with curcumin. The present stud thereby aims to determine the effects of curcumin on testicular blood vessels in experimentally-induced diabetic rats.

\section{MATERIAL AND METHODS}

\section{Induction and assessment of diabetes}

The study was carried on male Wistar rats (200-250 g). The experimental procedure of the animal research was approved by Srinakarinwirot University Medical Center Animal Care Committee., Thailand and the protocols were reviewed and approved. All animals were kept and maintained in a controlled animal laboratory environment on alternative 12-hour light/dark periods $\left(25+2^{\circ} \mathrm{C}\right)$, fed with standard rat chow and with access to water ad libitum. Experimental diabetic rats were induced by streptozotocin (STZ) (Sigma, St, Louis, MO, USA) 60 mg/BW dissolved in $0.1 \mathrm{~mol} / \mathrm{l}$ citrate buffer injected intravenously into the lateral tail vein. Control rats received injection with citrate buffer alone. The blood sugar level was measured and analyzed by one-touch glucometer after the last injected with STZ for three days. Rats with a blood sugar level $>250 \mathrm{mg} / \mathrm{dl}$ were considered diabetic. Control and diabetic rats were randomly assigned to one of three groups: control rats $(\mathrm{C})$, diabetic rats $(\mathrm{DM})$, and diabetic rats supplemented with curcumin (DMC) in corn oil daily (99.99\% pure, $200 \mathrm{mg} / \mathrm{kg} \mathrm{BW}$, Sigma, St. Louis, MO, USA). All animals were clinically observed and weighed weekly. At the end of 8 weeks after STZ injection or curcumin supplementation, the rats in each group were killed, the testis removed, dissected, and immediately fixed in Bouin's solution (Sigma, St, Louis, MO, USA) in preparation for histological study under a light microscope. For vascular corrosion casting technique, the rats of each group were used for studying the microvasculature of the testis by methyl methacrylate injection (Batson's no. 17) (Polysciences, Warrington, PA) and corroded with $10 \% \mathrm{KOH}$ solution combined with scanning electron microscopic (JEOL JSM-5400 SEM) observation. 


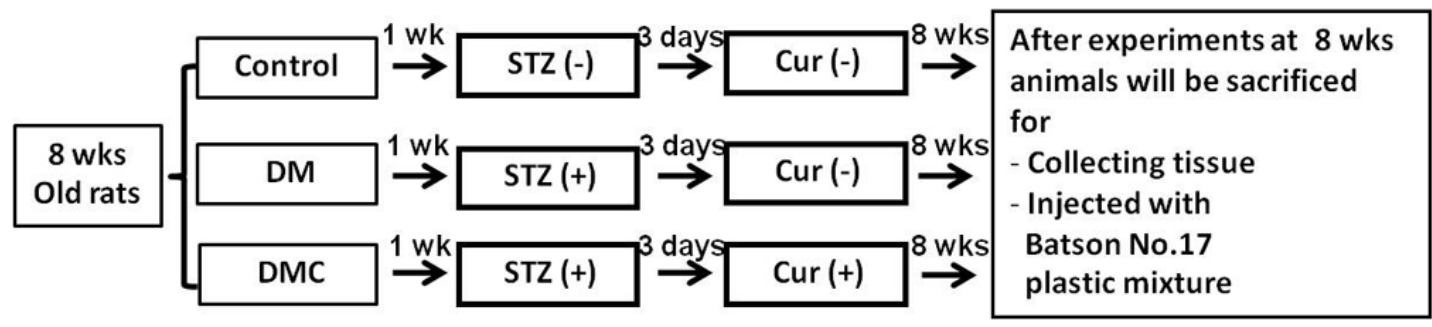

Figure 1. A flowchart of the experimental design.

\section{Histological preparation}

The testis was fixed in Bouin's solution overnight and then dehydrated in graded series of ethanol through 70, 80, 90, 95, and 100\% with two changes for 1 hour each. Three changes of xylene with 30 minutes each were used as clearing reagent before filtration. The tissue was embedded in paraffin, sectioned at $5 \mu \mathrm{m}$ thick, and then stained with hematoxylin and eosin $(\mathrm{H} \& \mathrm{E})$. All sections were examined and photographed using an Olympus light microscope (BX-50, Olympus, Japan).

\section{Vascular corrosion casting technique}

Each animal of every group was deeply anaesthetized with thiopental (i.p.), laid down on the metal mesh placing in the stainless tray. The thoracic cavity was opened by subcostal incision to create a chest flap that was closed clamped and retracted to expose the heart. Then, heparin, $0.5 \mathrm{ml}(5,000 \mathrm{IU} / \mathrm{ml})$ was quickly injected into the left ventricle and allowed to circulate for 1 to 2 minutes. The left ventricle was then pierced with a blunt no. 18-gauge needle and its tip directed towards the lumen of the ascending aorta. A needle was held in place with an arterial clamp. The right atrium was cut and opened, being the outlet part for blood, and fluid was injected. Approximately $400-500 \mathrm{ml}$ of $0.9 \% \mathrm{NaCl}$ solution was infused through a cannula until the effluent was clear. Then, Batson's no. 17 plastic mixture was immediately injected into the cannula, following the perfusion with $\mathrm{NaCl}$ solution through the ascending aorta. Each animal was left at room temperature to allow the casting medium to settle. The testis was excised and immersed in warm water $\left(80^{\circ} \mathrm{C}\right)$ to assure polymerization of the plastic. Testes were dissected and immersed in 10\% $\mathrm{KOH}$ for 30-60 days to let the tissue disintegrate, leaving a casting of the vessels. The specimens were rinsed in slow running tap water and washed several times with distilled water. The preparation was then dissected, trimmed under a stereomicroscope, and left to air dry. The vascular cast of testis was placed on a metal stub with double side adhesive tape, sprayed with carbon paint, and coated with gold on a sputtering apparatus. Finally, the casts were examined under the scanning electron microscope (JEOL JSM-5400) at accelerating voltage of $10 \mathrm{KV}$.

\section{Statistical analysis}

The diameter of testis blood vessels, the average diameter and epithelial thickness of seminiferous tubules were measured by SemAfore computer software program. The results were expressed as mean \pm standard error of the mean. Statistical analysis was performed by 
using ANOVA followed by Bonferroni posttest. A $p$-value smaller than 0.05 was considered statistically significant.

\section{RESULTS}

\section{Histological observations of testicular tissue}

The histological investigations of testicular tissue and blood vessels among three different groups of rats (control, DM, and DMC) throughout the 8 week experiment demonstrated that the testis in control group was encapsulated by thick fibrous connective tissue called tunica albuginea (Figure 2A) and subcapsular arteries (Figure 3A). All seminiferous tubules were surrounded by interstitial connective tissue. The interstitial connective tissue revealed the cluster of interstitial Leydig's cells and intratesticular vessels (Figure 2B). Seminiferous tubules were lined with many layers of normal organization and had compacted with spermatogenic cells. Spermatogonia lie on the basement membrane; spermatocytes are displayed above them; spermatids are arranged above the spermatocytes in one to two layers. In an ordinary seminiferous tubule, four age groups of cells develop at the same time and in correct organization with each other. As each age group of the cells grows, Sertoli cells support their movement through the epithelium until the fully formed sperm are released into the tubular lumen.
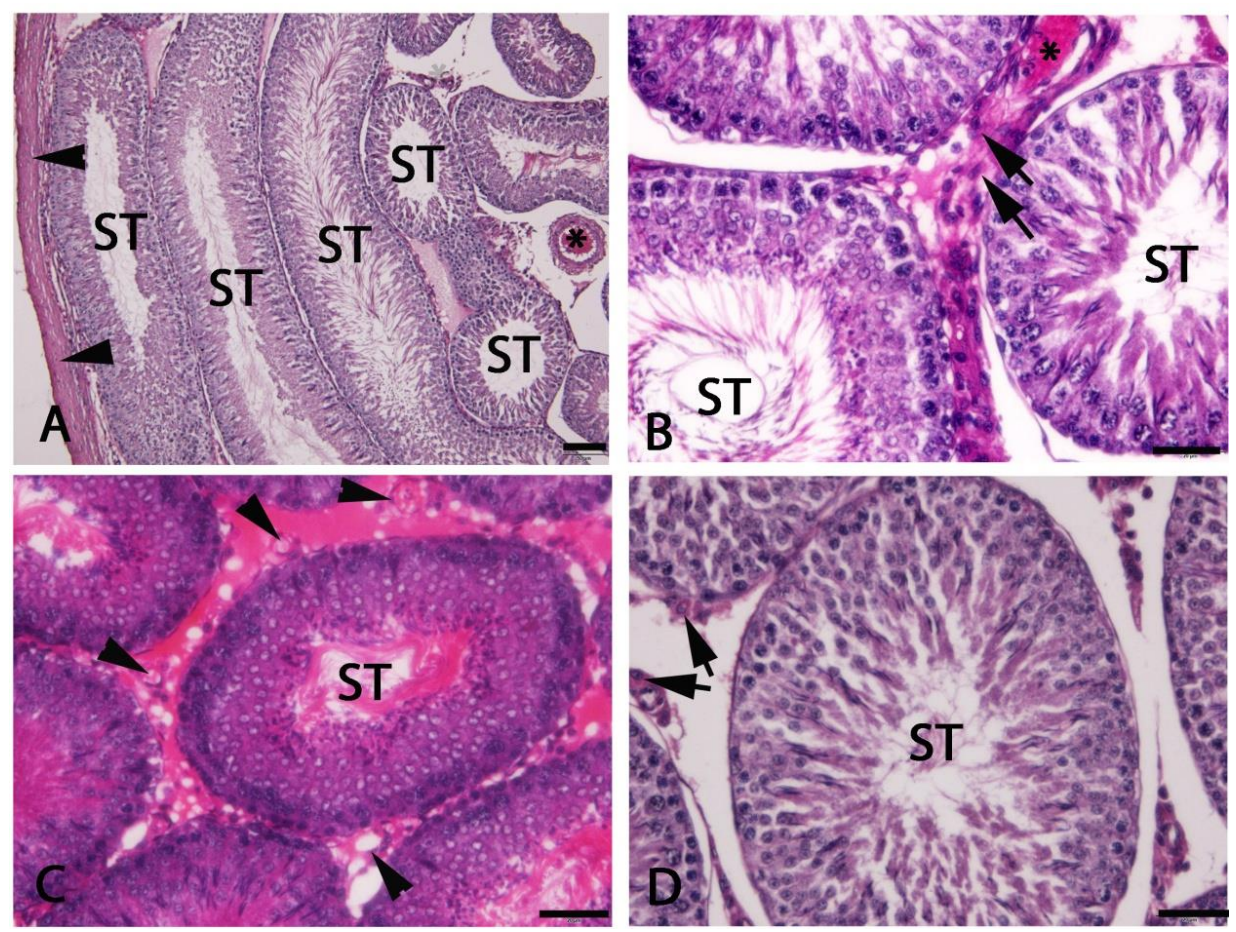

Figure 2. Light micrographs of testicular tissue of rats stained with H\&E. (A) control group, demonstrated the rat testis was encapsulated by tunica albuginea (arrowhead) and have many seminiferous tubules (ST) inside $(10 \mathrm{X})$. Bar $=50 \mu \mathrm{m}$. (B) Each ST was surrounded by interstitial connective tissue (arrow) that revealed the cluster of Leydig's cell and blood vessels. (asterisk) ST had compacted of spermatogenic cells. (40X). Bar $=20 \mu \mathrm{m}$. (C) DM group, illustrating ST revealed irregular in shape. The number of spermatogenic cell layer was reduced and germ cells degeneration. Interstitial spaces (arrow) showed exudate and apparently thickened blood vessels (arrowheads) (40X). Bar $=20$ $\mu \mathrm{m}$. (D) DMC group, showing recovering ST and spermatogenic cells and Leydig cells (arrows). (40X). Bar $=20 \mu \mathrm{m}$. 


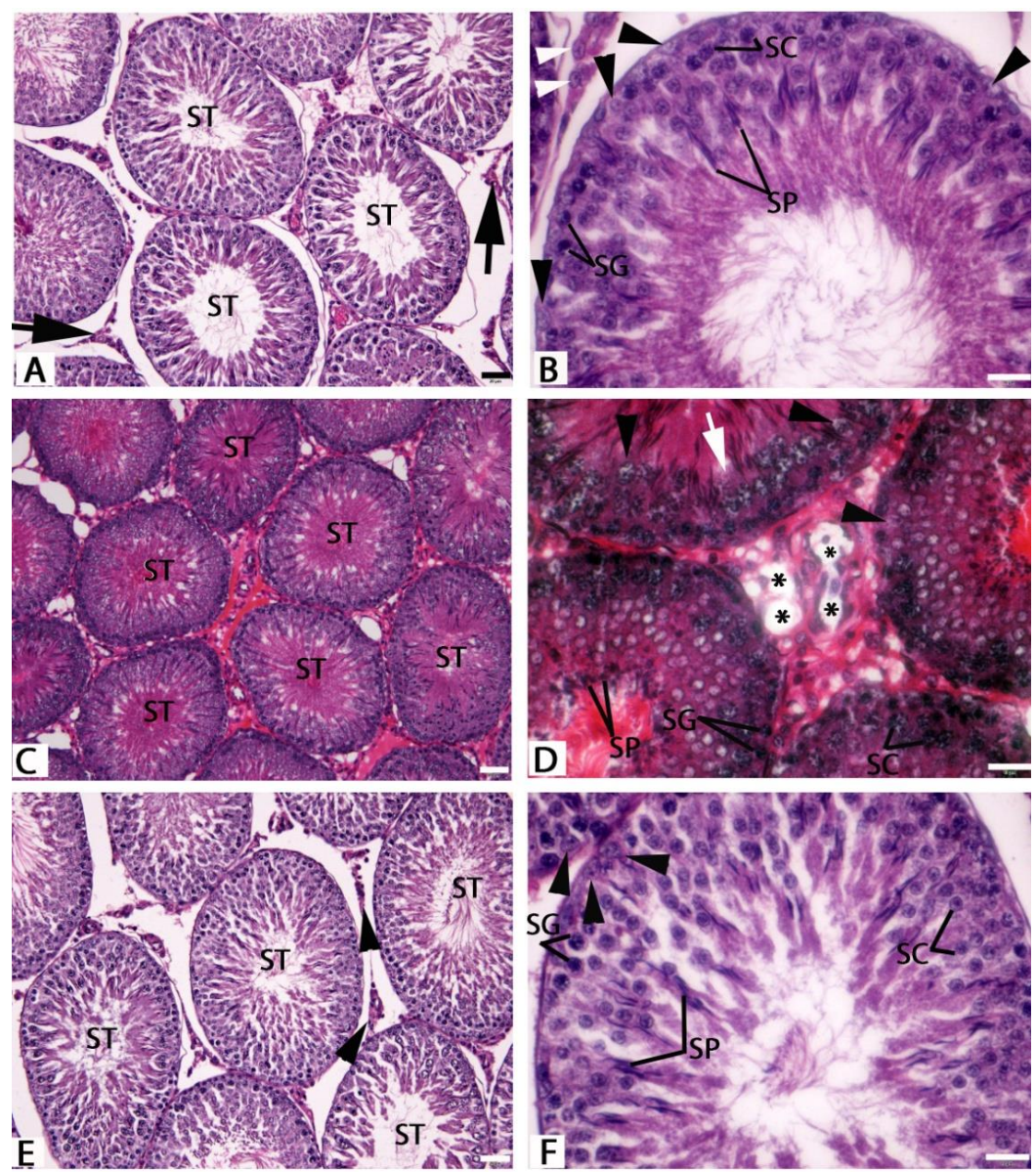

Figure 3. Light micrographs of testicular tissue of rats stained with H\&E. (A) Control group, the seminiferous tubules (ST) were surrounded by interstitial connective tissue with Leydig's cells (arrows) (20X). Bar $=20 \mu \mathrm{m}$. (B) ST epithelium was structurally intact and showed normal association of germ cells. The tubules had the cluster of Leydig cells (white arrowhead). This presentation indicated normal interstitial tissue, Sertoli cells (Black arrowhead). (60X). Bar $=10 \mu \mathrm{m}$. (C) DM group, illustrating the small diameter of ST (20X). Bar $=20 \mu \mathrm{m}$. (D) DM group, demonstrating the germ cells degeneration. Many ST were presented vacuoles in Sertoli cells (black arrowhead). Moreover, the multinucleated cells (white arrow) with two or three nucleus were revealed in some of seminiferous tubules. The thickened blood vessels (asterisks) were also seen. (60X). Bar $=10 \mu \mathrm{m}$. (E) DMC group, illustrating redeveloping of ST and Leydig's cells (black arrowhead). (20X). Bar $=20 \mu \mathrm{m}$. (F) DMC group, ST were presented normal spermatogenic and sertoli cell and Leydig cells $(60 \mathrm{X})$. Bar $=10 \mu \mathrm{m}$. SG $=$ spermatogonium, $\mathrm{SC}=$ spermatocytes, $\mathrm{SP}=$ spermatid

All types of spermatogenic cells demonstrated normal cellular attachment (Figures 1B, 2A and B). This presentation suggested that the interstitial tissue, Sertoli cells, and epithelium thickness were normal. The seminiferous tubules showed all the characteristic developmental stages of spermatogenesis. Spermatozoa were seen in the lumen of the tubules. The testicular tissue of DM group demonstrated abnormal histology. The damage in seminiferous tubules had irregular shape and small diameter. The illustrated seminiferous epithelium was altered from control rats in the distribution pattern. (Figures 1C, 2C). The number of spermatogenic cell layers was reduced, the spermatocytes and spermatids had necrosis, and the seminiferous tubules revealed a reduced number of sperms. Some tubules had few layers of spermatogenic cells with apparent no sperms and germ cells degeneration (Figures 1C, 2D). Many tubules presented vacuoles in Sertoli cells.

The multinucleated cells with two or three nuclei were also revealed in some of the seminiferous tubules. The basement membrane of seminiferous tubules thickened and interstitial connective tissue illustrated more abundant collagen fibers (Figures 2C, D). 
Moreover, interstitial spaces showed exudate (Figure 4C) and apparently thickened blood vessels (Figure 4D). The subcapsular arteries were encapsulated by tunica albuginea and the intratesticular arteries were located in the interstitial testicular tissue. Most of the small blood vessels had notably narrow lumens. The diameter of subcapsular artery and the intratesticular artery were seriously increased (Figure 4C and D). In the DMC group, all seminiferous tubules had normal spermatogenic cells (spermatocytes and spermatids) and Sertoli cells. Furthermore, the interstitial space between tubules had a normal appearance. Leydig cells also had a normal appearance but the thickness of the basement membrane and interstitial connective tissue decreased. The intratesticular artery appeared to have normal shape and size. The interstitial space between seminiferous tubules was also normal.
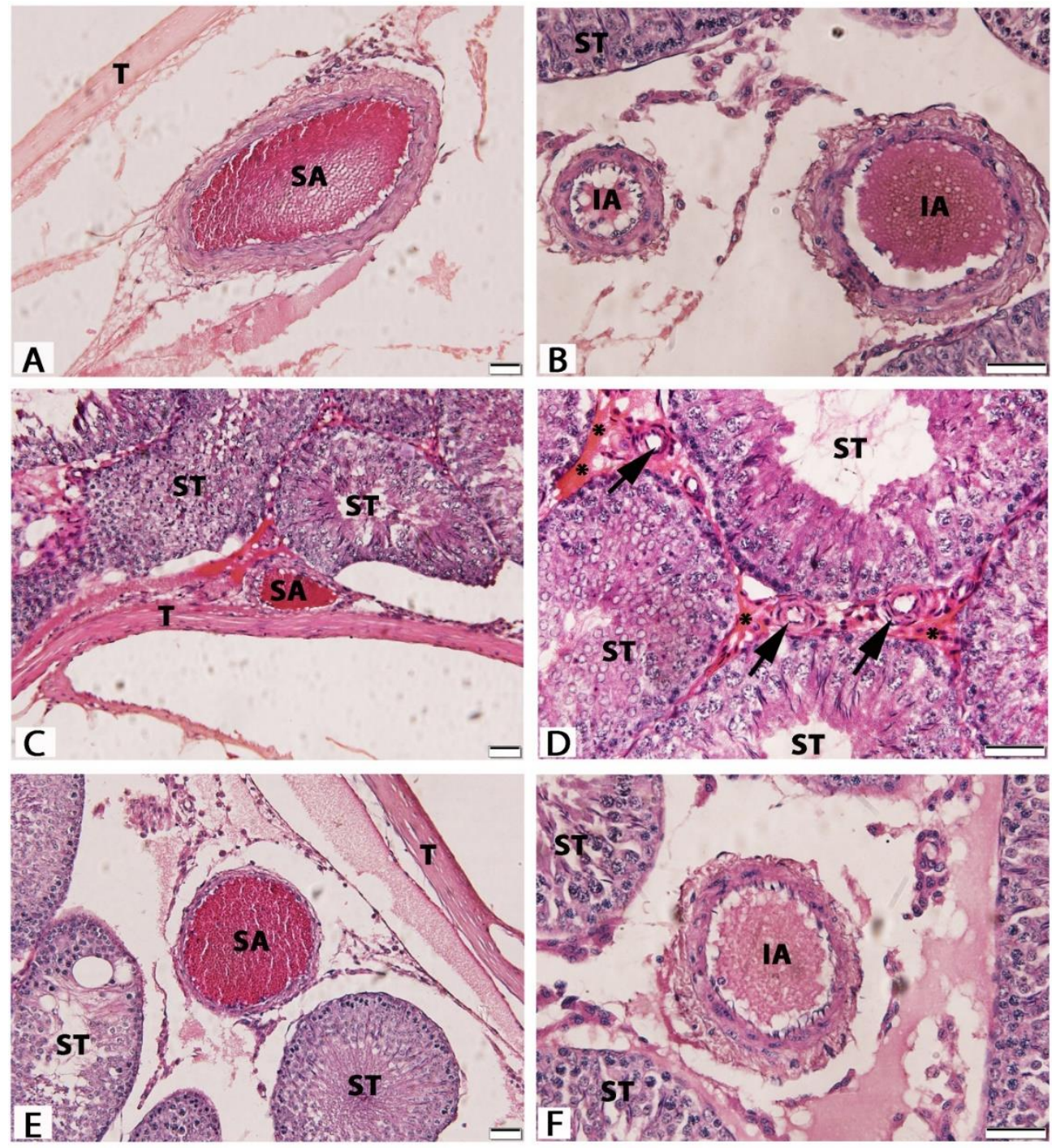

Figure 4. Light micrographs of blood vessels in testicular tissue of rats stained with H\&E. (A, B) Control group, A: The subcapsular artery (SA) that lined near tuniga albuginea $(\mathrm{T})(20 \mathrm{X})$. Bar $=20 \mu \mathrm{m}$. B: The intratesticular arteries (IA) demonstrated normal pattern of three layers of the wall and surrounded by interstitial loose connective tissue between seminiferous tubules (ST) (60X). Bar $=10$ $\mu \mathrm{m}$. (C, D) DM group, C: The subcapsular artery (SA) demonstrated the small diameter (20X). Bar = $20 \mu \mathrm{m}$. D: The intratesticular arteries (arrows) had shrinkage revealing the pathology of blood vessels. The interstitial connective tissue around blood vessels had an abundance of collagen fibers (asterisk), ST: seminiferous tubule (60X). Bar $=10 \mu \mathrm{m}$. (E, F) DMC group, E: The seminiferous tubules (ST) and intratesticular artery (IA) were an improvement and were the control group. (20X). Bar $=20 \mu \mathrm{m}$. (F): the appearance of all intratesticular artery (IA) all had a normal shape and size. The interstitial space between seminiferous tubules was quite natural. ST: seminiferous tubule (60X). Bar $=10 \mu \mathrm{m}$. 
The graph data of the average diameter (Figure 10) and epithelial thickness (Figure 11) of seminiferous tubules of DM group demonstrated significant decrease when compared to the control group ( $<<0.001, p<0.001$ respectively). In contrast, they were significantly increased after treatment with curcumin in DMC rats $(\mathrm{p}<0.01, \mathrm{p}<0.01$ respectively).

\section{Vascular corrosion casting technique to examine the testicular microvasculature}

The low magnification of vascular corrosion cast technique with stereomicroscope revealed the testis in control group at 8 weeks to be highly vascularized. The proximal portion of testicular artery (TA) (Figure 5) was straight along the testicular vein (TV) that become pampiniform plexus (PP), a loose network of small veins found within the male spermatic cord. Testicular artery become convoluted and surrounded by the pampiniform plexus descending directly onto the dorsal surface of the testicular blood vascular bed (Figure 5). This artery turned at the caudal pole of the testis and ascended onto the ventral surface of the testicular blood vascular bed. On this ventral surface, the testicular artery demonstrated 5-7 marked convolutions. Testicular artery finally enters into the testicular parenchyma close to the rostral pole, giving rise to 4-5 parenchymal branches (Figure 5). Afterwards, the parenchymal branches in the interstitial space divided into arterioles of various diameters with mesh of capillaries surrounding the distal portions of the capillaries, converging to form small venules that drained the blood into the collecting veins, respectively. Two collecting veins at both sides of the testis joined together, draining the blood into the pampiniform plexus.

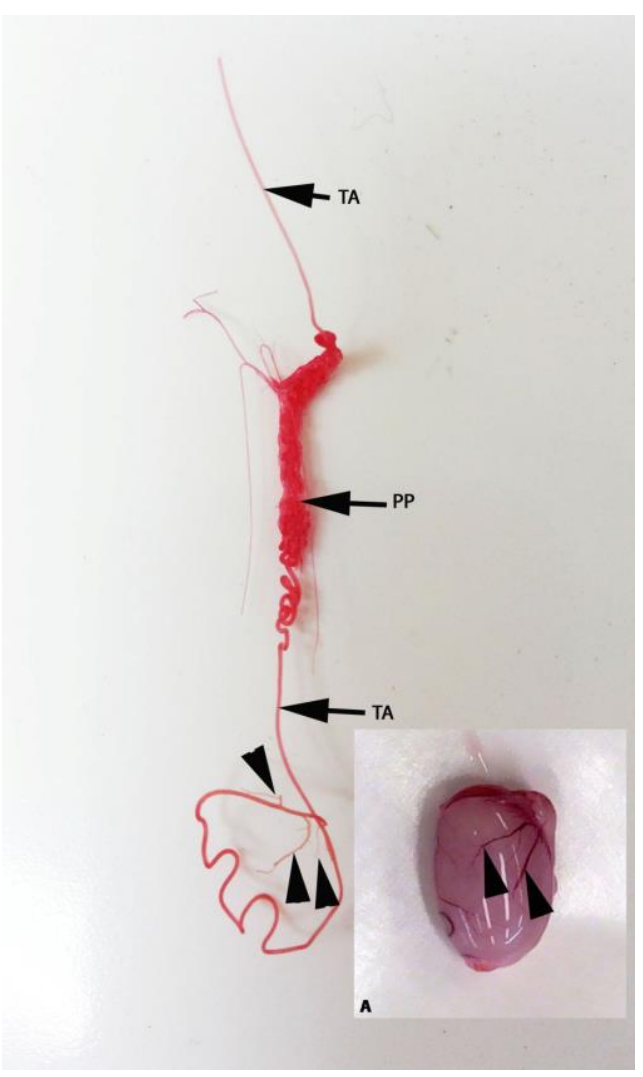

Figure 5. Photomicrograph of whole vascular cast in control rat's testis at 8 weeks. The proximal portion of testicular artery (TA) is somewhat straight. When the artery become the convoluting segments are surrounded by the pampiniform plexus (PP). Testicular artery finally penetrates into the testicular parenchyma near the rostral pole to give off 4-5 parenchymal branches (arrowhead) into testicular tissue. 
At high magnification, the testis vascular cast of large blood vessels in control group (Figure 6A, B) demonstrated that the testicular artery was in the typical pattern of coil artery in the spermatic cord and surrounded by pampiniform plexus. In contrast, in the DM group (Figure 6C), the testicular artery and veins in pampiniform plexus were destroyed and shrunk. Moreover, in the DMC group (Figure 6D), presented the testicular artery and pampiniform plexus recovered and redeveloped. At the level of small blood vessels in the testicular tissue, small arterioles came from the intratesticular artery in the interstitial spaces that gave branches into capillaries surrounding the seminiferous tubules. The distal portions of the capillaries converged to form small venules draining blood into the collecting vein. In the DM group, the destroyed capillaries were presented by the small diameter, stenosis and shrinkage of capillaries, arterioles, and venules respectively. After curcumin supplementation in DMC group, the redevelopment and restoration of capillary network, arterioles, and venules were evident.
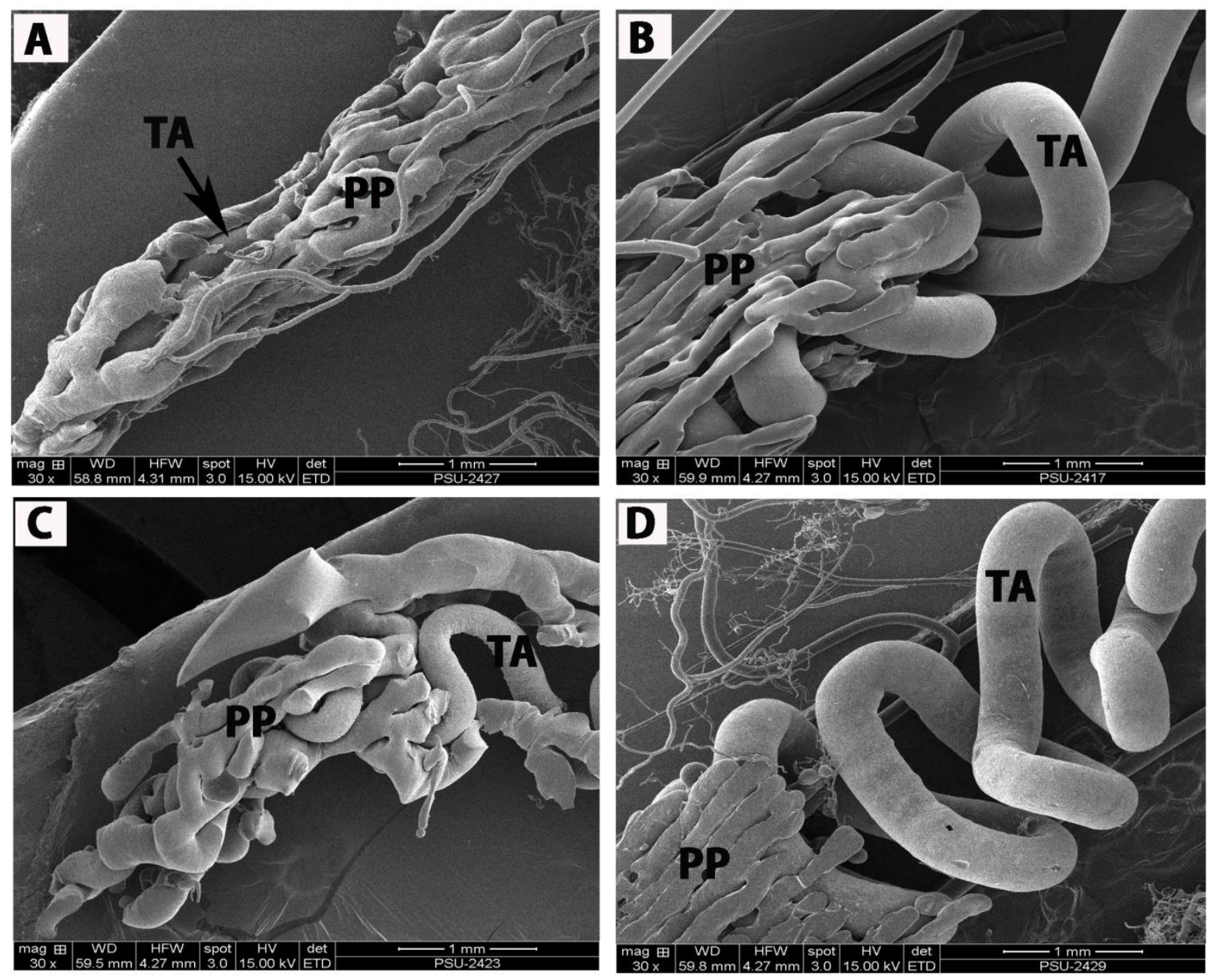

Figure 6. SEM micrographs of testis vascular cast of large blood vessels in rats at 8 weeks. (A, B) Control group, showing the testicular artery (TA) in the pattern of coil artery in the spermatic cord. It was surrounded by pampiniform plexus (PP). (C) DM group, demonstrated the destroyed and shrunken testicular artery (TA) and veins in pampiniform plexus (PP) (D) DMC group, presented the recovery and redevelopment of testicular artery (TA) and pampiniform plexus $(\mathrm{PP}) \mathrm{Bar}=1 \mathrm{~mm}$. 

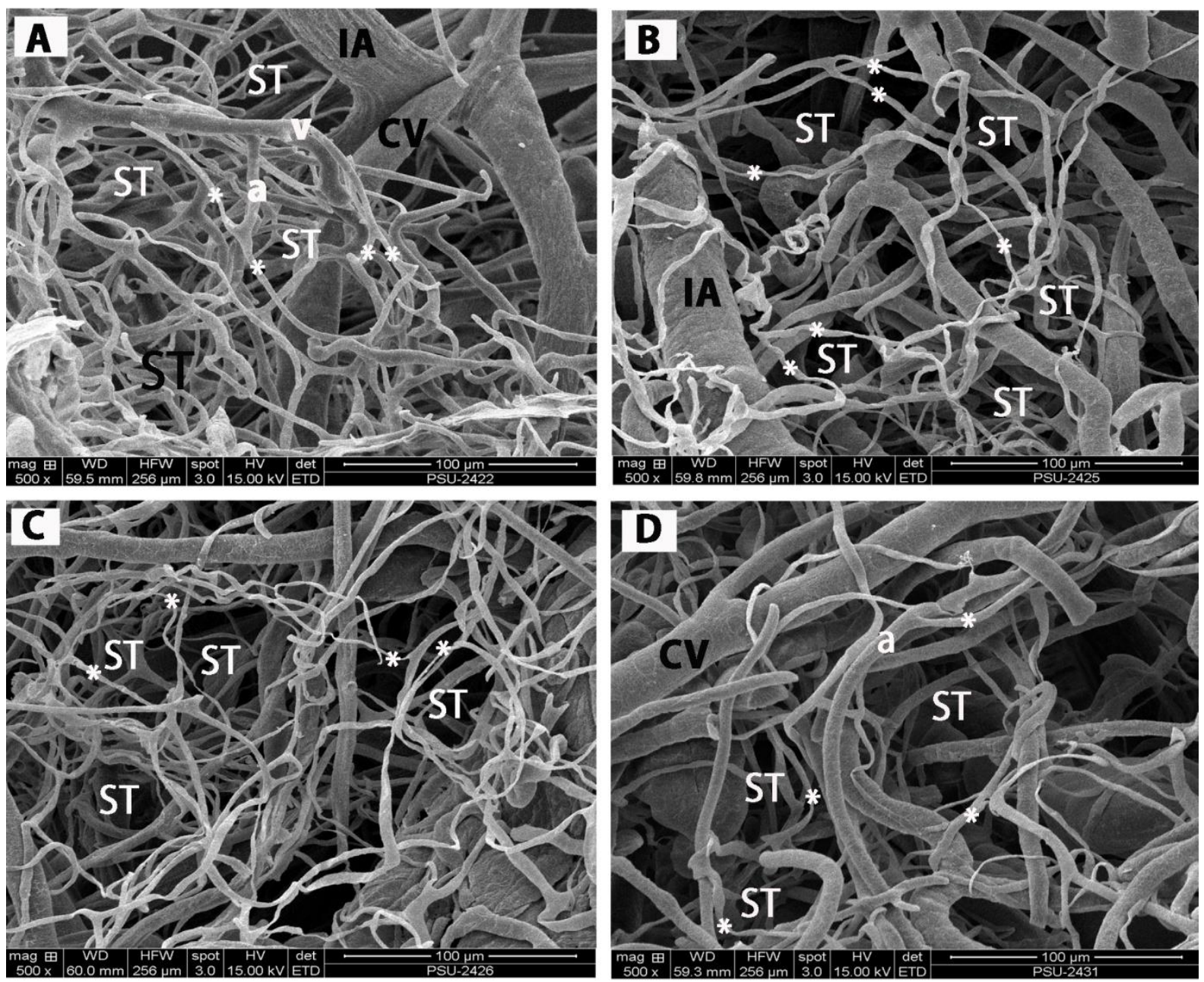

Figure 7. SEM micrographs of testis vascular cast of small blood vessels in rats at 8 weeks. (A) Control group, illustrating small arterioles (a) came from the intratesticular artery (IA) in the interstitial spaces gave branches into capillaries (white asterisk) rounded the seminiferous tubules (ST). Distal ends of the capillaries converged into small venules (V) and drained the blood into the collecting veins (CV), respectively. (B, C) DM group, destroyed capillaries were seen by presentation of stenosis and shrinkage of capillaries (white asterisk), arterioles and venules. (D) DMC group, the redevelopment and restoration of capillaries, arterioles and venules were evidently. $\operatorname{Bar}=100 \mu \mathrm{m}$.

The comparative diameter sizes of all vessels among C, DM, and DMC groups of the 8 week experiments were demonstrated in large and small types of vessel: TA, TV, PP (Figure 7), Intratesticular artery (IA), Intratesticular vein (IV), arterioles, venules, and capillaries (Figure 8). Diameters of DM vessels were critically decreased and much more severe compared to the control group. TA, TV, IA, IV, and arterioles demonstrated remarkable decrease in sizes more than once within the venules and capillary, through stenosis and shrinkage. Although diameters of pampiniform plexus had no difference among the three groups of rats, low density and aggregration of blood vessels in pampiniform plexus of DM group was seen. Significantly, the signs of vessel restoration and improvement were also presented by the increase of diameters of all types of vessels in the DMC experiment. The diameters of all the vessels were measured and compared in Figures 7 and 8. 


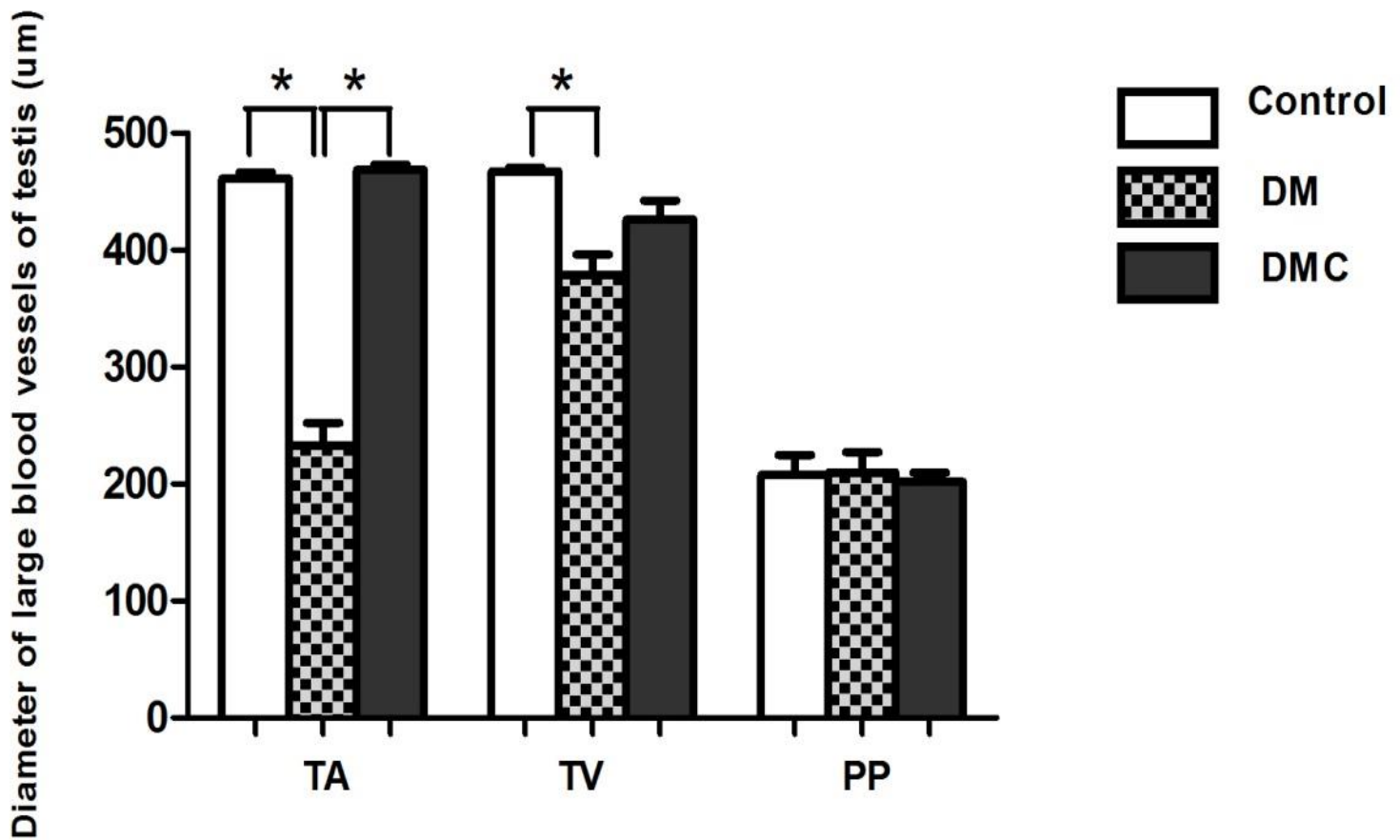

Figure 8. The average diameters of large blood vessels of testis: testicular arteries (TA), Testicular vein and Pampiniform plexus (PP) in control (C), diabetes (DM), and diabetes treated with curcumin $(\mathrm{DMC})$ rats at 8 weeks. Values are mean $+\mathrm{SE}, * \mathrm{P}<0.001$

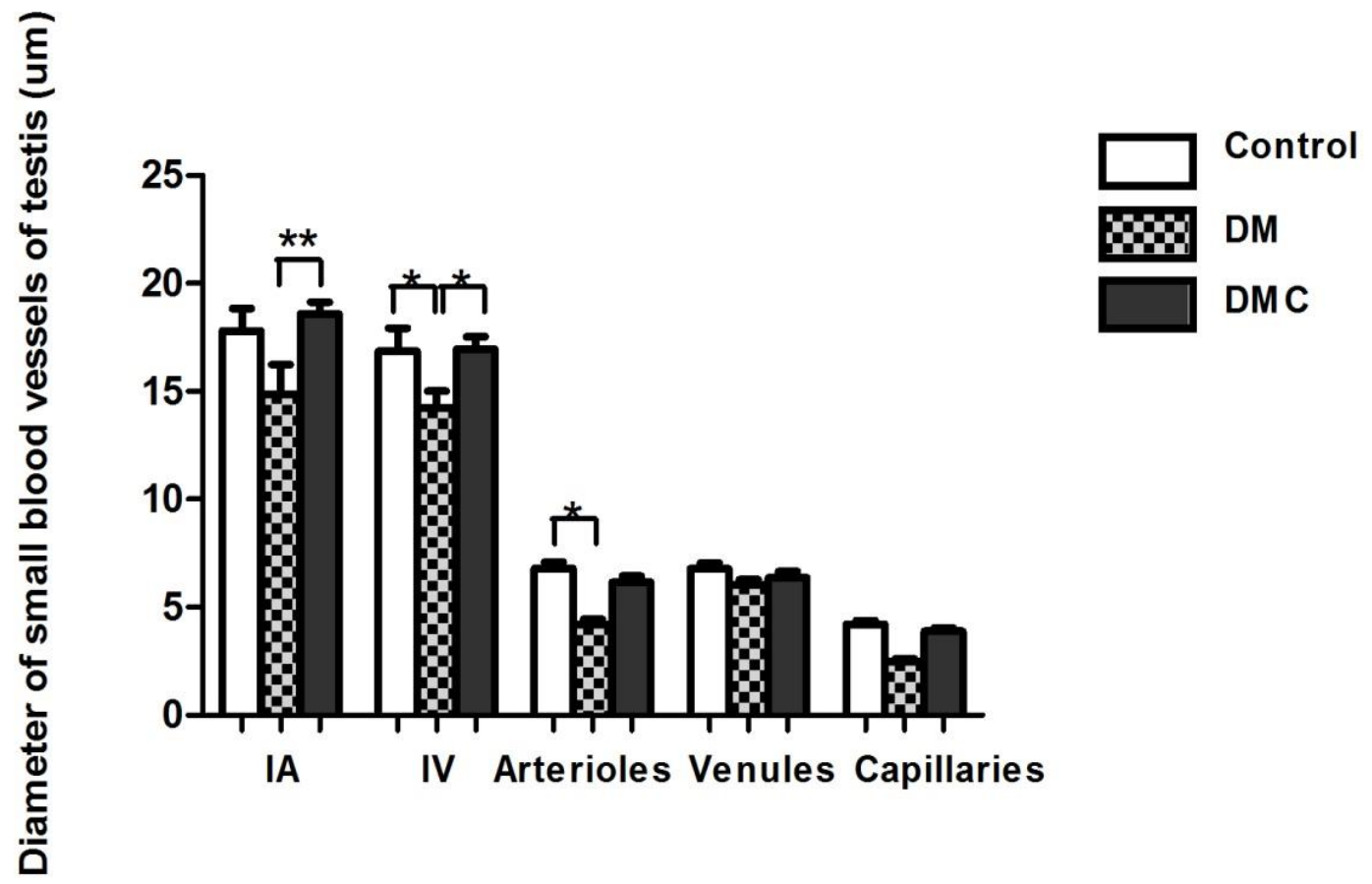

Figure 9. The average diameters of intratesticular arteries (IA), intratesticular vein (IV), arterioles, venules, and capillaries in control (C), diabetes (DM), and diabetes treated with curcumin $(\mathrm{DMC})$ rats at 8 weeks. Values are mean $+\mathrm{SE}, * \mathrm{P}<0.01, * * \mathrm{P}<0.05$ 
Figure 10. The average diameters of seminiferous tubules in the control (C), diabetes (DM), and diabetes treated with curcumin (DMC) rats at 8 weeks. Values are mean $+\mathrm{SE},{ }^{*} \mathrm{P}<0.001$, $* * \mathrm{P}<0.01$
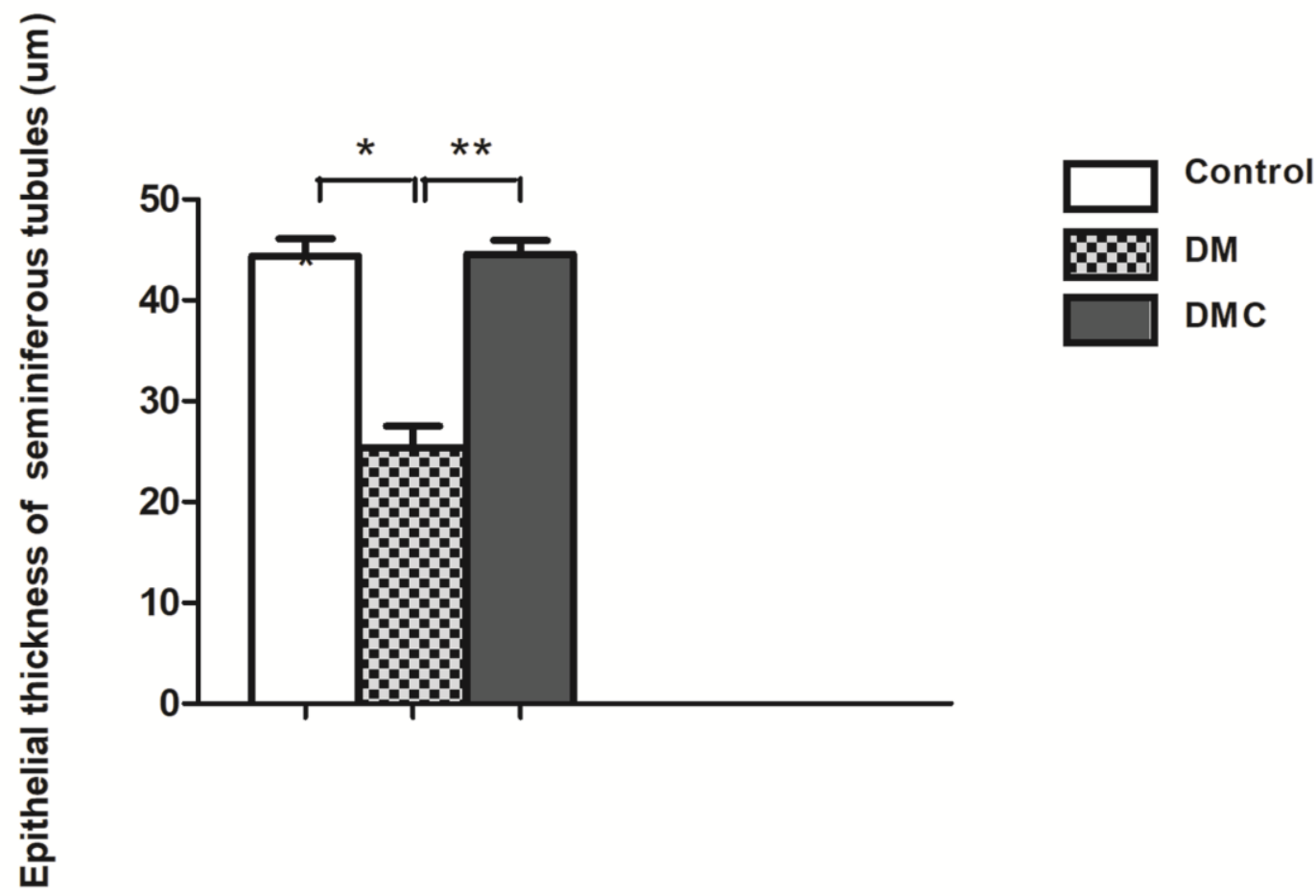

Figure 11. The average epithelial thickness of seminiferous tubules in control (C), diabetes $(\mathrm{DM})$, and diabetes treated with curcumin $(\mathrm{DMC})$ rats at 8 weeks. Values are mean $+\mathrm{SE}$, $* \mathrm{P}<0.001, * * \mathrm{P}<0.01$

The graph data of the DM large testicular blood vessels (Figure 8) demonstrated significant decrease in the diameter of TA and TV indices when compared to the control group ( $<<0.001)$. In contrast, the diameters of TA were significantly increased after treatment with curcumin in DMC rats ( $p<0.001)$. Additionally, the diabetic-diameters of small blood vessels (Figure 9), IV and arterioles decreased and were much more severe compared to the ones of control group 
$(\mathrm{p}<0.01)$. Furthermore, the diameter of IA and IV significantly increased after treatment with curcumin in DMC rats $(\mathrm{p}<0.05, \mathrm{p}<0.01$ respectively).

\section{DISCUSSION}

Diabetes is a regular health problem which impairs the sexual function of females and males. The hyperglycaemic condition of diabetes interrupts cellular metabolisms and affects the oxidative environments of the tissues and cells. Hyperglycaemia can disturb the testicular function by reducing the fertility of diabetic rat (38). In this study, the seminiferous tubules atrophied, becoming irregular in shape and revealing a small diameter accompanied by the reduction of sperm production in diabetic rats. Spermatogenic cells were reduced and degenerated. In diabetic male rats, Kanter et al. (37) demonstrated a reduction in testis weight, diameters of seminiferous tubules, spermatogenic cells, and blood serum testosterone levels. Furthermore, a reduction in Sertoli cells leads to a reduction in the number of sperms. Sertoli cells play an important role in spermatogenesis or production of sperm, providing physical support, nutrition, and generation of hormone signals essential for spermatogenesis [39]. A condition which decreases Sertoli cells also leads to a decreased number of germinal cells [40]. In diabetes-induced hyperglycemia, reactive oxygen and nitrogen species chemically modify intracellular macromolecules, including carbohydrates, lipids, nucleic acids, and proteins [41]. A consequence of hyperglycemia is an overproduction of reactive oxygen species (ROS) as a reaction of mitochondrial malfunction. Hyperglycaemia may damage blood vessels by upregulation of protein kinase $\mathrm{C}(\mathrm{PKC})$. As the hexosamine and polylol pathways are activated, there is an increase in the production of advanced glycation end products (AGE) and an upregulation of RAGE receptors. Since glucose is taken up in several tissues, a mechanism independent of insulin, an increase in serum glucose raises the intracellular glucose concentration [42]. An increase in the generation of ROS alongside the weakening of the antioxidant defense system leads to oxidative stress. In diabetic patients, oxidative stress results from hyperglycaemia which stimulates the production of several reducing sugars via the polyol pathway and glycolysis pathways, decreasing the capacity of endogenous antioxidants. The effects of diabetes on the vasculature is considerable. Diabetes impairs the endothelium and smooth muscle cells. However, diabetes also perturbs platelets, lipoproteins, local vasoactive substances, clotting factors, and triglycerides. Diabetes enhances the local response to hypoxia and the formation of new collateral vessel [43]. In diabetic rats, the diameter of subcapsular artery and the intratesticular artery were seriously decreased. Diameters of DM vessels from vascular casting were critically decreased and much more severe compared to the control group. TA, TV, IA, IV, and arterioles revealed remarkable decreases in sizes more than ones of venules and capillary that were seen by presentation of stenosis and shrinkage. Interestingly, the signs of vessel restoration and improvement were also presented alongside the increase of diameters of all types of vessels in DMC experiment. Thus, a common long-term complication of diabetes is vascular disease which damages blood vessels all over the body.

Insulin resistance and oxidative stress are directly related in mediating the cardiovascular complications of diabetes. Insulin helps to maintain the important physiological function of endothelium. Insulin is able to induce NO release through the activation of the PI3K-Akt signaling cascade leading to serine phosphorylation of eNOS. In an insulin resistant condition, the PI3K signalling decreases, activating the mitogen-activated protein kinase (MAPK) and increasing the secretion of ET-1, resulting in endothelial dysfunction [44]. This disfunction is 
characterized by an inability of arteries and arterioles to dilate properly in response to a suitable stimulus by vasodilators. This endothelial dysfunction is related to a decrease in the NO bioavailability, which may be the result of reduced NO synthesis by the endothelial cells or by deactivation of NO by caused by ROS [45].

Curcumin plays an important role in ameliorating diabetic vascular disease by modulating PKC- $\alpha$, PKC- $\beta 2$, and recovering STZ-induced testicular damage, oxidative stress, and apoptosis possibly via regulation of NADPH oxidase activity and the MAPK pathway [46-48]. In an experimental model of diabetic cardiomyopathy, curcumin prevents accumulation of AGE collagen and cross-linking of collagen in the tendon and skin [49]. Curcumin decreases oxidative DNA and protein damage via a decrease in endothelial nitric oxide synthase (eNOS) and an induction of nitric oxide synthase (iNOS). In STZ rats, curcumin debilitated diabetesinduced vascular dysfunction by enhancing the ratio of prostanoidmetabolites PGI (2)/TXA (2) via suppression of cyclooxygenase- $2(\mathrm{COX}-2)$ activity, NF- $\kappa \mathrm{B}$, and $\mathrm{PKC}$ [50]. In hypertension associated diabetic rats, curcumin induces heme oxygenase-1 (HO-1) normalizing the vascular contractility via a reduction in TNF- $\alpha$ and ROS [51]. In STZ-rats [52] and mice [53], curcumin is able to improve the endothelial dysfunction by its own antioxidant activity and by inhibiting PKC.

According to vascular complication, our previous works have continuously established that curcumin restores and reforms microvascular architectures in the STZ-induced diabetes, (including in the liver) and choroid vessels in eyes and heart [54-56]. The research findings show the potential effects of curcumin as therapeutic agent on diabetic complications. Considering the intake of curcumin in the daily diet could be recommended the antiinflammatory and antioxidant properties of curcumin should be carefully considered [57].

\section{CONCLUSION}

The results of our study demonstrated that the effects of curcumin could improve the destruction of the testicular microvasculature and tissues in diabetic rats. Interestingly, the signs of vessel restoration and improvement were presented by increasing the diameters of all types of vessels in DMC experiment that study by vascular corrosion casting. The vessels diameter increased back to a quasi-normal condition, particularly at the artery, arteriole, and capillary levels. The reconstruction and restoration of testicular artery, pampiniform plexus, capillary network, arterioles, and venules were restored. This study could be useful in examining the role of curcumin as a natural remedy in the damage of testicular and vascular tissue caused by diabetes.

List of Abbreviations: C, control; DM, diabetic; SEM, scanning electron microscope; STZ, streptozotocin; TA, testicular artery; TV, testicular vein; PP, pampiniform plexus; IA, intratesticular artery; IV intratesticular vein.

Competing Interests: The authors declare no conflict of interest.

Authors' Contributions: VA and WK designed and conducted the research and performed the vascular corrosion casting. MK and PB assisted for tissue preparation and staining methods. WK and VA wrote the manuscript and performed statistical analysis. All authors read and approved the final version of the manuscript. 
Acknowledgments and Funding: This work was supported by a grant from the Faculty of Science Research Fund under the Grant No. SCI581456S-0. The authors are thankful to Mrs. Anna Chatthong for improving the English of this manuscript.

\section{REFFERENCES:}

1. McCance DR, Hanson RL, Pettitt DJ, Bennett PH, Hadden DR, and Knowler WC: Diagnosing diabetes mellitus-do we need new criteria? Diabetologia 1997, 40: 247255.

2. Hviid A, Stellfeld M, Wohlfahrt J, and Melbye M: Childhood vaccination and type 1 diabetes. The New England Journal of Medicine 2004, 35: 1398-1404.

3. Burke JP, Jacobson DJ, McGree ME, et al.: Diabetes and sexual dysfunction: results from the Olmsted County study of urinary symptoms and health status among men. $\mathbf{J}$ Urol 2007, 177: 1438-42.

4. Arsov T, Silva DG, O’Bryan MK, Sainsbury A, Lee NJ, Kennedy C, et al.: Fat aussiea new Alstrom syndrome mouse showing a critical role for ALMS1 in obesity, diabetes, and spermatogenesis. Molecular Endocrinology 2006, 20(7): 1610-22.

5. Frenkel G, Homonnai Z, Drasnin N, Sofer A, Kaplan R, Kraicer P.: Fertility of the Streptozotocin-Diabetic Male Rat. Andrologia 1978, 10(2): 127-36.

6. Scarano WR, Messias AG, Oliva SU, Klinefelter GR, Kempinas WG: Sexual behaviour, sperm quantity and quality after short-term streptozotocin-induced hyperglycaemia in rats. Int J Androl 2006, 29: 482-488

7. Warren S, and LeCompte P: The pathology of diabetes mellitus. Lea and Febiger, Phladelphia 1952, 73.

8. Schloffing K. Hypogonadism in male diabetic subjects: From On the nature and treatment of diabetes. Edited by B. Leibel and G. Wrenshall. Amsterdam: Excerpta Medic 1965; 505-521.

9. Cameron DF, Murray FT, and Drylie DD. Interstitial compartment pathology and spermatogenic disruption in testes from impotent diabetic men. Anat Rec; 1985: 213: 53-62.

10. Lusis AJ: Atherosclerosis. Nature 2000, 407(6801): 233-41.

11. Bolzan, AD, Bianchi MS. Genotoxicity of Streptozotocin: Mutat Res 2002, 512: 12134.

12. Ammon HP, Safayhi H, Mack T, Sabieraj J: Mechanism of anti-inflammatory actions of curcumine and boswellic acids. J Ethnopharmacol 1993, 38: 113-9.

13. Reddy AC, Lokesh BR: Studies on anti-inflammatory activity of spice principles and dietary n-3 polyunsaturated fatty acids on carrageenan-induced inflammation in rats. Ann Nutr Metab 1994, 38: 349-58.

14. Joe B, Lokesh BR: Effect of curcumin and capsaicin on arachidonic acid metabolism and lysosomal enzyme secretion by rat peritoneal macrophages. Lipids 1997, 32: 117380.

15. Xu YX, Pindolia KR, Janakiraman N, Noth CJ, Chapman RA, Gautam SC: Curcumin, a compound with anti-inflammatory and anti-oxidant properties, down-regulates chemokine expression in bone marrow stromal cells. Exp Hematol 1997, 25: 413-22.

16. Chun KS, Keum YS, Han SS, Song YS, Kim SH, Surh YJ: Curcumin inhibits phorbol ester-induced expression of cyclooxygenase-2 in mouse skin through suppression of 
extracellular signal-regulated kinase activity and NF-kappaB activation. Carcinogenesis 2003, 24: 1515-24.

17. Philip S, Kundu GC: Osteopontin induces nuclear factor kappa B-mediated promatrix metalloproteinase-2 activation through I kappa B alpha /IKK signaling pathways, and curcumin (diferulolylmethane) down-regulates these pathways. J Biol Chem 2003, 278 : 14,487-97.

18. Shishodia S, Potdar P, Gairola CG, Aggarwal BB: Curcumin (diferuloylmethane) down-regulates cigarette smoke-induced NF-kappaB activation through inhibition of I kappaB alpha kinase in human lung epithelial cells: correlation with suppression of COX-2, MMP-9 and cyclin D1. Carcinogenesis 2003, 24: 1269-79.

19. Jobin C, Bradham CA, Russo MP, Juma B, Narula AS, Brenner DA, et al.: Curcumin blocks cytokine-mediated NF-kappa B activation and proinflammatory gene expression by inhibiting inhibitory factor I-kappa B kinase activity. J Immunol 1999, 163: 347483.

20. Bae MK, Kim SH, Jeong JW, Lee YM, Kim HS, Kim SR, et al.: Curcumin inhibits hypoxia-induced angiogenesis via down-regulation of HIF-1. Oncol Rep 2006, 15: 1557-62.

21. Choi H, Chun YS, Kim SW, Kim MS, Park JW: Curcumin inhibits hypoxia inducible factor-1 by degrading aryl hydrocarbon receptor nuclear translocator: A mechanism of tumor growth inhibition. Mol Pharmacol 2006, 70(5): 1664-71.

22. Kobayashi T,Hashimoto S, Horie T: Curcumin inhibition of Dermatophagoides farineainduced interleukin-5 (IL-5) and granulocyte macrophage-colony stimulating factor (GM-CSF) production by lymphocytes from bronchial asthmatics. Biochem Pharmacol 1997, 54: 819-24.

23. Abe Y, Hashimoto S, Horie T: Curcumin inhibition of inflammatory cytokine production by human peripheral blood monocytes and alveolar macrophages. Pharmacol Res 1999, 39: 41-7.

24. Hidaka H, Shiko T. Furuhashi T, Kamohara H, Suzuki S, Miyazaki M, Ikeda O, et al.: Curcumin inhibits interleukin 8 production and enhances interleukin 8 receptor expression on the cell surface: impact on human pancreatic carcinoma cell growth by autocrine regulation. Cancer 2002, 95: 1206-14.

25. Natarajan C, Bright JJ.: Curcumin inhibits experimental allergic encephalomyelitis by blocking IL-12 signaling through Janus kinase-STAT pathway in T lymphocytes. J Immunol 2002, 168: 6506-13.

26. Tomita M, Holman BJ, Santoro CP, Santoro TJ: Astrocyte production of the chemokine macrophage inflammatory protein- 2 is inhibited by the spice principle curcumin at the level of gene transcription. J Neuroinflammation 2005, 2: 8.

27. Santibanez JF, Quintanilla M, Martinez J: Genistein and curcumin block TGFbeta 1induced u-PA expression and migratory and invasive phenotype in mouse epidermal keratinocytes. Nutr Cancer 2000, 37: 49-54.

28. Mohan R, Sivak J, Ashton P, Russo LA, Pham BQ, Kasahara N, et al.: Fini, Curcuminoids inhibit the angiogenic response stimulated by fibroblast growth factor2, including expression of matrix metalloproteinase gelatinase B. J Biol Chem 2000, 275: 10, 405-512. 
29. Masamune A, Suzuki N, Kikuta K, Satoh M, Satoh K, Shimosegawa T: Curcumin blocks activation of pancreatic stellate cells. J Cell Biochem 2006, 97: 1080-93.

30. Chaudhary LR, Hruska KA.: Inhibition of cell survival signal protein kinase B/Akt by curcumin in human prostate cancer cells. J Cell Biochem 2003, 89: 1-5.

31. Liu JY, Lin SJ, Lin JK: Inhibitory effects of curcumin on protein kinase C activity induced by 12-O-tetradecanoyl-phorbol-13-acetate in NIH 3 T3 cells. Carcinogenesis 1993, 14: 857-61.

32. Chen YR, Tan TH.: Inhibition of the c-Jun N-terminal kinase (JNK) signaling pathway by curcumin: Oncogene 1998, 17: 173-8.

33. Squires MS, Hudson EA, Howells L, Sale S, Houghton CE, Jones JL, et al.: Relevance of mitogen activated protein kinase (MAPK) and phosphotidylinositol-3-kinase/protein kinase $\mathrm{B}(\mathrm{PI} 3 \mathrm{~K} / \mathrm{PKB})$ pathways to induction of apoptosis by curcumin in breast cells. Biochem Pharmacol 2003, 65: 361-76.

34. J Biol Chem.: Ca2+-ATPase of sarcoplasmic reticulum but increases the rate of accumulation of Ca2+. J Biol Chem. 2001, 276: 46, 905-11.

35. Mahmmoud YA: Curcumin modulation of Na,K-ATPase: phosphoenzyme accumulation, decreased $\mathrm{K}+$ occlusion, and inhibition of hydrolytic activity. $\mathrm{Br} \mathrm{J}$ Pharmacol 2005, 145: 236-45.

36. Kang J, Chen J, Shi Y, Jia J, Zhang Y: Curcumin-induced histone hypoacetylation: The role of reactive oxygen species. Biochem Pharmacol 2005, 69: 1205-13.

37. Kanter M, Aktas C, Erboga M: Curcumin attenuates testicular damage, apoptotic germ cell death, and oxidative stress in streptozotocin-induced diabetic rats. Mol Nutr Food Res 2012, 56: 1-8.

38. Cameron DF, Rountree J, Schultz RE, Repetta D, Murray FT: Sustained hyperglycemia results in testicular dysfunction and reduced fertility potential in BBWOR diabetic rats. Am J Physiol 1990, 259: E881-E889.

39. Okamura M, Watanabe T, Kashida Y, Machida N, Mitsumori K: Possible mechanisms underlying the testicular toxicity of oxfendazole in rats. Toxicol Pathol, 2004; 32: 1- 8.

40. Richburg JH.: The relevance of spontaneous- and chemically induced alternation in testicular germ cell apoptosis to toxicology. Toxicol Lett 2000, 112-113: 79-86.

41. Kushwaha S and Gena GB: Telmisartan ameliorates germ cell toxicity in the STZinduced diabetic rat: Studies on possible molecular mechanisms. Mutation research 2013, 755: 11-23.

42. Giacco F, Brownlee M: Oxidative stress and diabetic complications. Circ Res 2010, 107(9): 1058-70.

43. Beckman JA, Creager MA, Libby P: Diabetes and atherosclerosis: epidemiology, pathophysiology, and management. JAMA 2002, 287(19): 2570-81.

44. Kim JA, Montagnani M, Kwang KK, Quon MJ: Reciprocal relationships between insulin resistance and endothelial dysfunction: molecular and pathophysiological mechanisms. Circulation 2006, 113(15): 1888-1904.

45. Kaneto H, Katakami N, Matsuhiss M, Matsuoka TA: Role of reactive oxygen species in the progression of type 2 diabetes and atherosclerosis. Mediators of Inflammation 2010, 453892(11): 2010. 
46. Soetikno V, Sari FR, Sukumaran V: Curcumin prevents diabetic cardiomyopathy in streptozotocin-induced diabetic rats: possible involvement of PKC-MAPK signaling pathway. European Journal of Pharmaceutical Sciences 2012, 47(3): 604-614.

47. Zha W, Bai Y. Zu L, Liu Y, Yang Z, Gao H and Li J: Curcumin Attenuates Testicular Injury in Rats with Streptozotocin-Induced Diabetes. BioMed Research International 2018. DOI: https://doi.org/10.1155/2018/7468019

48. Kukongviriyapan U, Apaijit K and Kukongviriyapan V: Oxidative Stress and Cardiovascular Dysfunction Associated with Cadmium Exposure: Beneficial Effects of Curcumin and Tetrahydrocurcumin. Tohoku J Exp Med 2016, 239: 25-38.

49. Sajithlal GB, Chithra P, Chandrakasan G: Effect of curcumin on the advanced glycation and cross-linking of collagen in diabetic rats. Biochemical Pharmacology 1998, 56(12): 1607-1614.

50. Rungseesantivanon S, Thengchaisri N, Ruangvejvorachai P, Patumraj S: Curcumin improves prostanoid ratio in diabetic mesenteric arteries associated with cyclooxygenase- 2 and NF- $\kappa \mathrm{B}$ suppression Diabetes. Metabolic Syndrome and Obesity. Targets and Therapy 2010, 3: 421-429.

51. Hassan, El-Bassossy HM, Zakaria N: Heme oxygenase-1 induction protects against hypertension associated with diabetes: effect on exaggerated vascular contractility. Naunyn-Schmiedeberg's Archives of Pharmacology 2013, 386(3): 217-226.

52. Patumraj S, Wongeakin N, Sridulyakul P, Jariyapongskul A, Futrakul N, Bunnag N: Combined effects of curcumin and vitamin $\mathrm{C}$ to protect endothelial dysfunction in the iris tissue of STZ-induced diabetic rats. Clinical Hemorheology and Microcirculation 2006, 35(4): 481-489.

53. Rungseesantivanon S, Thenchaisri N, Ruangvejvorachai P, Patumraj S: Curcumin supplementation could improve diabetes-induced endothelial dysfunction associated with decreased vascular superoxide production and PKC inhibition. BMC Complementary and Alternative Medicine 2010, 10(57).

54. Khimmaktong W, Petpiboolthai H, Panyarachun B, Anupunpisit V: Study of curcumin on microvasculature characteristic in diabetic rat's liver as revealed by vascular corrosion cast/scanning electron microscope (SEM) technique. J Med Assoc Thai 2012, 95 (Suppl 5): S133-141.

55. Khimmaktong W, Petpiboolthai H, Sriya P, Anupunpisit V: Effects of curcumin on restoration and improvement of microvasculature characteristic in diabetic rat's choroid of eye. J Med Assoc Thai 2014, 97 (Suppl 2): S39-46.

56. Anupunpisit V, Petpiboolthai H, Khimmaktong W: Microvasculature Improvement of Heart in Diabetic Rat with Curcumin Supplementation J Med Assoc Thai 2015, 98 (Suppl 10): S74-83.

57. Chuengsamarn S, Rattanamongkolgul S, Luechapudiporn R, Phisalaphong C, Jirawatnotai S: Curcumin extract for prevention of type 2 diabetes. Diabetes Care 2012, 35: 2121-7. 